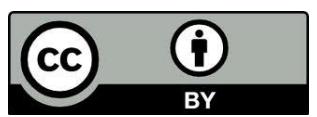

\title{
ESPAÇO E LUGAR SAGRADO: VIVÊNCIA E PERCEPÇÃO PENTECOSTAL ASSEMBLEIANA
}

Sacred Space and Place: Assembly of God Pentecostal Experience and Perceptions

\author{
Luana Cristina Baracho de Moura \\ Mestre em Geografia pelo PPGEO da \\ Universidade do Estado do Rio de Janeiro - UERJ \\ Coordenadora Pedagógica da SEEDUC/RJ \\ luana.cb.moura@gmail.com
}

\begin{abstract}
RESUMO: Este estudo objetiva produzir reflexão sobre o conceito geográfico de lugar sagrado. O grupo social religioso selecionado para esta ponderação é integrante da Igreja Assembleia de Deus - $\mathrm{AD}$, que se caracteriza como protestante e pentecostal e se difundiu espacial e culturalmente pelo Brasil a partir de 1911, impondo suas marcas à paisagem geográfica e à sociedade pelos últimos cem anos. $\mathrm{O}$ foco deste estudo incide sobre a interpretação de como o grupo social religioso membro da Igreja Assembleia de Deus Jardim 25 de Agosto constrói, percebe e vivencia o lugar sagrado. Através da análise das informações obtidas a partir da aplicação de um questionário a uma amostra qualitativa do grupo e de observações empíricas, foi possível obter informações que respondem satisfatoriamente ao objetivo inicial, além de produzir novos questionamentos, configurando este estudo em uma reflexão introdutória.
\end{abstract}

Palavras-chaves: Pentecostal; Lugar Sagrado; Igreja Assembleia de Deus.

ABSTRACT: This study aims to produce reflection on the geographical concept of sacred place. The religious social group selected for this purpose is a member of Assembly of God (Assembleia de Deus - AD), which is characterized as a Protestant and Pentecostal and spread spatially and culturally in Brazil since 1911; imposing their brands to the geographical landscape and society for the past hundred years. The focus of this study concerns on how the social group, as a religious member of Assembleia de Deus Jardim 25 de Agosto, builds, perceives and experiences the sacred place. Through the analysis of information obtained from a questionnaire to a sample group and from qualitative empirical observations, it was possible to obtain the data that respond satisfactorily our initial inquiry, beside s producing new questions; setting this study as an introductory reflection.

Keywords: Pentecostal; Holy Place; Assembly of God Church. 


\section{INTRODUÇÃO}

Uma das tarefas da Ciência Geográfica é democratizar o saber geográfico e induzir a sociedade a refletir sobre a geograficidade de suas ações cotidianas, ponderando sobre elas e desenvolvendo a sua inteligência espacial (SANTOS, 2007). Esta pesquisa contribui para tornar inteligível a ação humana sobre o espaço geográfico a partir da reflexão sobre a construção do Lugar. Sendo uma porção do espaço que se destaca ao provocar sentimentos positivos no grupo ou indivíduo, o lugar torna-se fundamental no enfoque cultural-humanista da geografia. A classificação de um espaço como lugar sagrado é apreendida através da vivência e percepção do homem religioso. Portanto, lançamos um olhar geográfico sobre a igreja Assembleia de Deus (AD) enfocando a percepção desse grupo social religioso sobre lugar sagrado.

Na obra As Formas Elementares da Vida Religiosa, o sociólogo Durkheim (1989) destaca como categorias dos fenômenos religiosos as crenças e os ritos. Assim, a percepção diz respeito às crenças e reflexões; já a vivência, refere-se às práticas, aos ritos; ambos podem ser analisados através das informações obtidas a partir de uma amostra qualitativa dos membros da Igreja Assembleia de Deus Jardim 25 de Agosto (ADJ25A). A apreciação baseia-se na análise de um questionário individual proposto aos membros da ADJ25A presentes em reunião regular de Escola Bíblica Dominical (EBD). As questões propostas possibilitam a interpretação de como o grupo constrói, percebe e vivencia o lugar sagrado. A escolha desta igreja como objeto de estudo se justifica pela relativa facilidade de acesso ao grupo para observação empírica e aplicação dos questionários qualitativos, aliada ao fato de se configurar como uma das igrejas Assembleias de Deus de referência no Município de Duque de Caxias, Estado do Rio de Janeiro.

Este estudo comporta em sua metodologia a análise teórica, através da apreciação de pesquisadores importantes na temática, a observação empírica, o exame de dados secundários obtidos através de Censos Demográficos do Instituto Brasileiro de Geografia e Estatística (IBGE) e a análise de dados primários obtidos através da elaboração e aplicação de um questionário ao grupo em tela. 
A Geografia da Religião se desenvolve no Brasil como um subcampo de pesquisa da Geografia Cultural e tem no espaço sagrado um de seus objetos de estudo mais proeminentes. Geógrafos, como Zeny Rosendahl (1993) e Sylvio Fausto Gil Filho (2003) desenvolvem intensos estudos sobre essa temática. Os estudos de Rosendahl (1997, 1999, 2002, 2003a, 2003b, 2005, 2008, 2009, 2012a, 2012b) têm como base de interpretação as ideias de Mircea Eliade, enfocando o sagrado em sua dimensão espacial como manifestação cultural. Entretanto, Gil Filho (2001, 2002, 2009, 2012) aborda a natureza fenomenológica do sagrado como objeto da geografia do sagrado, a partir da interpretação de Rudolf Otto e de Ernst Cassirer.

\section{Convergências entre Mircea Eliade e Zeny Rosendahl}

Na obra O Sagrado e o Profano (2010), o filósofo romeno naturalizado norteamericano, Mircea Eliade, interpreta o sagrado e o profano como duas modalidades do ser no mundo. Eliade apresenta o homem religioso e procura compreender a sua visão de mundo; como esse homem interpreta e vivencia o mundo através de suas crenças e ritos. Essa busca é realizada a partir da análise do homem primitivo e suas práticas religiosas. Segundo o autor, o homem religioso qualifica o espaço como heterogêneo, apresentando roturas e vivencia o espaço sagrado como sendo o eixo central de toda a sua orientação. No espaço sagrado, destaca-se o "ponto fixo", local da hierofania, e sua área de entorno. Eliade apresenta hierofania como sendo a manifestação do sagrado em pessoas, animais, objetos e coisas. A partir dessa manifestação, o objeto passa a representar algo que o transcende e sacraliza. Em contrapartida, o homem a-religioso descende do religioso e é resultado de um processo de dessacralização da existência humana. Eliade (2010, p. 173) defende que,

De uma perspectiva cristã poder-se-ia dizer igualmente que a não religião equivale a uma nova 'queda' do homem: o homem a-religioso teria perdido a capacidade de viver conscientemente a religião e, portanto, de compreendê-la e assumi-la; mas, no mais fundo de seu ser, ele guarda ainda a recordação dela. 
A hierofania pode ocorrer de duas maneiras: illo tempore, no momento em que ocorre, e através de um ritual de repetição. Illo tempore expressa a noção de tempo mítico, que é um tempo original, o início onde o mito aconteceu. Através de um ritual de repetição, o tempo mítico é tornado presente. Eliade diferencia tempo sagrado e tempo profano, sendo o primeiro relativo ao período das festas religiosas nas quais o tempo mítico é re-atualizado; ao segundo, corresponde a duração temporal ordinária na qual se inscrevem os atos privados de significado religioso, a vida cotidiana.

A partir dos estudos de Mircea Eliade, a geógrafa Rosendahl (2010) ressalta o sagrado e o profano em três dimensões de análise: (1) a dimensão econômica, (2) a dimensão política e (3) a dimensão do lugar. Na dimensão econômica, a autora enfatiza itens dos Bens Simbólicos, os Mercados e as Redes. Em relação à dimensão política, destaca os itens da Religião, território e territorialidades, Religião civil, sacralidade e sua identidade. Na dimensão do lugar, a proposta da pesquisadora abrange as seguintes temáticas: difusão da fé, comunidade e identidade; hierópolis, a construção de uma teoria; percepção, vivência e simbolismo e paisagem religiosa e região cultural.

Sobre a dimensão espacial do sagrado, Rosendahl (1999, p. 231) especifica: “a palavra sagrado tem o sentido de separação e definição, em manter separadas as experiências envolvendo uma divindade, de outras experiências que não envolvem, consideradas profanas”. Portanto, o espaço sagrado é separado e consagrado. A autora (2012a, p. 27) enfatiza que "apesar da onipresença de Deus, existem espaços que são mais sagrados do que outros". Tomando por base a definição de Eliade dos componentes do espaço sagrado como sendo o "ponto fixo" e o seu entorno, Rosendahl especifica o espaço profano como a área em torno do centro onde estão o "ponto fixo" e o seu entorno. A autora classifica em: (a) espaço profano diretamente vinculado ao sagrado, (b) espaço profano indiretamente vinculado ao sagrado e (c) espaço profano remotamente vinculado ao sagrado. Em relação à dinâmica da manifestação do poder do sagrado, podem ser reconhecidas três tipologias de espaço sagrado: (1) o fixo, (2) o não fixo-móvel e (3) o imaginalis. Como exemplos do espaço sagrado fixo a geógrafa citou as cidades-santuário; não-fixo, a Torá e imaginalis, o círculo sagrado de Wiccan. Nas reflexões de Rosendahl (1997, p. 149) o homem "reconstrói teoricamente o papel do sagrado na recriação do espaço, reconhecendo o sagrado não como simples aspecto da paisagem, mas como elemento de produção do espaço”. Rosendahl (idem, 1999, 2009, 
2012b) assinala, ainda, que a noção de espaço sagrado, vinculado à perspectiva humanística da geografia, ressalta a familiaridade com o lugar e a experiência compartilhada, tornando-se subjetiva por abranger a percepção do grupo religioso envolvido.

\section{Sylvio Fausto Gil Filho e o espaço sagrado a partir de Otto e Cassirer}

Nos estudos de Gil Filho (2012) a percepção do sagrado pode ser interpretada no reconhecer o espaço sagrado em seu caráter de palco privilegiado das práticas religiosas. O geógrafo propõe estudá-lo como uma projeção simbólica da realidade religiosa e conclui que "o espaço sagrado está muito mais próximo de um espaço da percepção do que dos espaços concebidos pelo intelecto. Dessa maneira, o espaço sagrado é produto da consciência religiosa concreta" (GIL FILHO, 2012, p. 63). O autor enfatiza o papel da experiência religiosa do indivíduo, relacionando o espaço sagrado mais ao fiel e à sua experiência do que ao espaço geográfico especificamente. Nas palavras de Pereira e Gil Filho (2012, p. 43-44):

Seria mais propriamente uma conjunção de espacialidades da experiência religiosa do que uma base material. [...] Nesse sentido o espaço sagrado não estaria na(s) coisa(s), mas sim nos sujeitos/indivíduos. Nesse caso o protagonista da trama do Espaço Sagrado seria o homem religioso, o fiel.

O geógrafo estuda o espaço sagrado em uma perspectiva locacional, abrangendo a rede de relações e os significados criados a partir de experiências religiosas. Suas pesquisas têm por fonte as considerações de Rudolf Otto sobre o Sagrado e a Fenomenologia de Ernst Cassirer. Baseado em Cassirer, Gil Filho passa a atentar para o universo simbólico no qual o homem vive e as representações conseqüentes dele (GIL FILHO E GIL, 2001; GIL FILHO, 2002; PEREIRA e GIL FILHO, 2010, 2012). 
Em seu artigo $O$ conceito de lugar na Geografia Cultural-Humanista: uma contribuição para a geografia contemporânea, Holzer (2003) explicita que "lugar" é considerado um conceito fundamental na geografia. Neste sentido, Rosendahl (2005) comunga com a proposta de Norton (2000) na qual a reflexão sobre o conceito de lugar na Geografia Cultural inclui os seis seguintes pontos:

i. A criação de lugares é um ato social; os lugares diferem porque as pessoas o fizeram assim;

ii. Os lugares são entidades auto-reprodutoras porque são contextos nos quais as pessoas aprendem e fornecem modelos de papel para socialização, alimentando determinadas séries de crenças e atitudes;

iii. Nenhuma cultura regional existe separadamente das pessoas que a refazem enquanto a vivem;

iv. Em uma economia capitalista mundial, lugares não são unidades autônomas cujas residentes têm controle independente sobre seus destinos;

v. Lugares não são simplesmente os resultados não-intencionais de processos econômicos, sociais e políticos;

vi. Lugares são potenciais fontes de conflito.

A geógrafa distingue o apontamento de lugar como potencial fonte de conflito como uma das principais preocupações dos geógrafos culturais (ROSENDAHL, 2005). No entanto, interessa a esta pesquisa refletir sobre a criação de lugar como um ato social, especificamente a interpretação de lugar sagrado na concepção de um determinado grupo social religioso. Sobre isso, Mello (1990, p. 92) expõe que "a geografia humanística defende uma maneira diferente de se pesquisar o espaço e o lugar, longe da verdade única de um pensador dominado por teorias que 'explicam' o mundo". Neste sentido, a

Abordagem humanista se apóia nas filosofias dos significados tais como a fenomenologia, o existencialismo, o idealismo e a hermenêutica - procurando compreender, por intermédio da experiência vivida pelos indivíduos e grupos sociais, o que é o mundo vivido. Para tanto, o pesquisador deve entranhar-se, sem preconceitos nos significados que os seres atribuem aos espaços e lugares, visando a compreender suas alegrias e carências, para 
então influir e agir na construção de um espaço mais humanizado (ibidem, p. 92).

Espaço e lugar estão entre os conceitos-chave nas pesquisas geográficas. Mello (1993, p. 32) esclarece:

No âmbito da vertente humanística, espaço e lugar são distintos. O espaço é amplo, desconhecido, temido e rejeitado. O lugar, recortado afetivamente, onde as pessoas se sentem seguras e à vontade, emerge nas experiências cotidianas, nos locais de moradia, trabalho, compras, lazer e encontros. Para o humanismo em geografia, na simbiótica relação entre homens e meio ambiente, lugares devem ser considerados como pessoas e pessoas como lugares. Por conseguinte, para esta escola de pensamento - surgida nos anos 70 e apoiada nas filosofias do significado - cada ser humano é um geógrafo informal, pois é o homem que cria, atua e vive no espaço, estando portanto capacitado para discorrer sobre o seu mundo vivido, pleno de mistérios, entendimentos, significados, devaneios, premências, rejeições, fantasias, satisfações e reminiscências.

“O lugar - vivido, concebido, místico, sagrado, transitório ou eterno - em sua complexa teia de formulações tem sido um traço marcante na obra de Tuan, um dos expoentes da geografia humanística", apregoa Mello (2001, p. 94). Sendo ratificado por Holzer (2003, p. 121), segundo o qual, "Tuan, com toda certeza foi dos principais responsáveis pela valorização do "lugar" como conceito central dos estudos geográficos”. Comungando com ambos os geógrafos, Mello e Holzer, a compreensão humanista desenvolvida por Yi-Fu Tuan sobre o conceito de lugar permeará este estudo focado na proposição temática indicada por Rosendahl (2002), Espaço e Lugar Sagrado: vivência, percepção e simbolismo.

O geógrafo Tuan (1983) diferencia os conceitos de espaço e lugar; o primeiro significando liberdade e o segundo, segurança. Para o autor, lugar é uma pausa no movimento, um centro calmo de valores estabelecidos, é um mundo de significado organizado. A conformação de um espaço em sagrado comporta o desenvolvimento de laços de afetividade, configurando-o ao mesmo tempo como lugar, pois, "o processo de criação [de lugar sagrado] contribui para que lugares e objetos se tornem parte de nossa auto-identidade, assim como o contato repetido, a familiaridade com o lugar e a 
experiência partilhada" (ROSENDAHL, 2010, p. 205). Esse processo foi definido por Tuan (1980) como Topofilia, ou seja, o elo afetivo entre a pessoa e o lugar ou ambiente físico. Uma das propostas de Rosendahl (2002) para abordagem geográfica no estudo do sagrado e profano relaciona a dimensão do Lugar, através da percepção, da vivência e do simbolismo criado pelos grupos sociais. Para a autora (1997, p. 121), "espaço sagrado é o lócus de uma hierofania, isto é, uma manifestação do sagrado", que ocorre somente mediante a fé humana. Rosendahl (1997, p. 122) acrescenta à sua definição de espaço sagrado a qualidade de "um campo de forças e de valores que eleva o homem religioso acima de si mesmo, que o transporta para um meio distinto daquele no qual transcorre sua existência". O espaço sagrado é separado do profano e posto em destaque.

Boa parte das igrejas cristãs consideram os seus templos espaços sagrados por excelência. Pereira (2010) observa que o espaço sagrado não é apenas um receptáculo, mas também a fonte irradiadora da sacralização.

\section{Assembleia de Deus - AD no Brasil}

O Movimento Pentecostal se difundiu pelo mundo e chegou ao Brasil no início do século XX. Ao analisar o pentecostalismo brasileiro, o sociólogo Freston (1994) conclui que as primeiras igrejas pentecostais que chegaram no país foram a Congregação Cristã e a Assembleia de Deus, designadas por Mariano (2005) como igrejas representantes do pentecostalismo clássico.

A Igreja Assembleia de Deus - AD representa o grupo religioso que se caracteriza como protestante e pentecostal e tem sua doutrina baseada em um livro sagrado, a Bíblia, considerando-a como a Palavra de Deus. Denomina-se protestante por seguir os princípios difundidos pela Reforma Protestante, provocada pelas ideias de Martinho Lutero; e pentecostal por defender a atualidade do batismo com o Espírito Santo, os dons de cura e a glossolalia, enunciados proféticos em línguas desconhecidas. A adesão a esse grupo segue os seguintes parâmetros: reconhecimento público e batismo por imersão do corpo inteiro uma só vez em águas, em nome do "Pai, do Filho e do Espírito Santo", realizando o simbolismo aquático semelhante ao descrito por 
Eliade (2010) no qual a imersão na água simboliza a morte do indivíduo e o seu renascimento para uma nova vida. Novos membros quando oriundos por transferência de outras igrejas evangélicas, dispensam um novo batismo nas águas.

A inauguração de novos templos possibilita a sua difusão pelo espaço geográfico, se reproduzindo e permitindo sua continuidade através de gerações, como ressalta Corrêa (1995, p. 55):

Se durante o processo de produção não se pensar na sua continuidade, sua própria reprodução, este cessará quando se finalizar a operação iniciada. É necessário que se criem no próprio processo de produção as condições de sua reprodução; sendo assim, o processo de produção é também de reprodução. Um grupo social tem a mesma necessidade; caso contrário, teríamos o absurdo do mesmo durar apenas o período de uma geração.

A difusão espacial da $\mathrm{AD}$ é realizada através da nucleação, criação de pequenos núcleos que funcionam como pontos de pregação da Bíblia Sagrada. O crescimento desses núcleos dá origem a novas filiais. Cada igreja inaugurada representa para o grupo religioso uma bandeira fincada como símbolo da conquista de um novo território, fortalecendo ainda mais a fé dos seus membros e possibilitando a associação de novos seguidores, como disserta Rosendahl (2002, p. 65): “o homem religioso, desta maneira se exprime sob as formas simbólicas que se relacionam no espaço. Cada vez que se ergue uma nova igreja, o grupo religioso tem a impressão de que cresce e se consolida". Assim, em 2011, ao completar o seu primeiro centenário no Brasil, as Assembleias de Deus se destacaram como a maior denominação pentecostal do país, respondendo por $6,5 \%$ dos brasileiros, somando 12,3 milhões de pessoas (IBGE, 2012).

A geógrafa Rosendahl (2012) esclarece em seus estudos duas possíveis concepções da manifestação do sagrado no espaço: a tradicional e a (pós-)moderna. Na concepção tradicional do estudo do sagrado defendida por Eliade o poder milagroso está no espaço sagrado, lócus da hierofania que se revela nas coisas, objetos e pessoas no espaço; o devoto busca o sagrado neste espaço, lugar fortemente impregnado das revelações do divino. Na concepção pós-moderna, o poder milagroso estaria dentro do peregrino, mas só se manifestaria no lugar sagrado. O peregrino é possuidor dessa força que se manifesta no lugar, em vivência no espaço, em ritual apropriado para tal 
manifestação. Para ambos, o espaço é o lócus da hierofania. E o geógrafo estudioso do espaço e do lugar está em condições de interpretar essas manifestações religiosas.

No pentecostalismo assembleiano, a hierofania também ocorre no lugar sagrado. No entanto, na interpretação pentecostal, qualquer espaço pode tornar-se lugar sagrado, ainda que provisoriamente, através da consagração feita por um grupo de crentes. Nesta percepção, o poder do sagrado estaria dentro do crente, mas só se manifestaria na vivência espiritual do grupo no lugar (con)sagrado. Mello (1990, p. 104) confirma que "um local pode ser espaço ou lugar em questão de horas" e cita o seguinte exemplo:

O Teatro Brigitte Blair II, na Cinelândia, Rio de Janeiro especializado de terça a domingo, em peças e revistas eróticas se transforma a cada segunda-feira em uma casa de orações do Grupo Renascer do Centro Evangélico. Quer dizer, para os evangélicos, em um único dia da semana, essa casa de espetáculos se torna lugar (sagrado) (ibidem, p. 107).

Para o pentecostalismo assembleiano, ao se dispensar o excesso de formalidade nas liturgias e permitir que leigos e incultos desfrutem do direito de pregar o Evangelho, o homem se aproxima de Deus. Reuniões destinadas aos cultos, rituais religiosos, passaram a ser realizadas não somente no templo, mas também em outros espaços, públicos e privados, como praças públicas e residências de membros do grupo. Pereira e Gil Filho (2009, p. 9) sugerem a seguinte definição para o culto:

Teologicamente, o termo "culto", do latim cultus ("veneração"), pode significar a mais elevada homenagem que se presta a uma divindade. Na maioria das vezes, tal designação é dada a reunião devocional do corpo comunal/integrante de determinada fé. Ou seja, é o lugar têmporo-espacial onde ocorrem, e se materializam, os procedimentos/práticas e as ideologias religiosas.

Os cultos religiosos realizados pelas Assembleias de Deus no Brasil tiveram seu início em uma residência particular e a prática se perpetuou na Instituição. Deus não estaria mais limitado ao espaço sagrado edificado pela igreja, o grupo poderia invocá-lo em outros lugares, tornados temporariamente sagrados. Eliade (2010) refere-se ao tempo sagrado como sendo o tempo destinado às festas religiosas. A hierofania ocorre 
em consequência de um ritual que busca a transcendência e evoca o tempo sagrado. Assim, no pentecostalismo, tempo sagrado não corresponderia somente ao tempo relativo às festas religiosas, mas também, ao tempo dedicado aos rituais religiosos, como cultos pentecostais. Pereira e Gil Filho (2009, p. 6) concordam que:

O Espaço Sagrado é algo intrínseco ao fenômeno religioso. Pois está diretamente ligado à sua manifestação. Desta forma ele é temporal e espacial, e, também, constituído por espacialidades do sagrado. De igual forma, aqui já inferindo um pouco de nossa pesquisa, no sistema pentecostal, o sagrado também se revela espacialmente; seja nas manifestações físico-espirituais (como a glossolalia), seja no lugar onde ocorrem os cultos ou ainda em atitudes rituais. Por este prisma, o culto evangélico pentecostal se mostra por excelência como o espaço e tempo sagrado.

E concluem que na cerimônia de Santa Ceia na AD:

A ligação entre o sagrado e o ser que o experimenta, é, desta forma, transferido para o espaço onde os ritos, as crenças, as instituições se materializam. O local onde acontece a cerimônia representa, assim, parte de um espaço sagrado. Pois, é neste lugar que o poder transcendental interage com os fieis: o poder ilimitado do divino entra em contato com o poder limitado da criatura (idem p. 11).

A sacralidade é apreendida subjetivamente e pode ser percebida através do comportamento humano. Em relação à sacralidade do lugar e a utilização de espaços públicos para os cultos, temos o seguinte exemplo: durante o período em que um culto estivesse sendo realizado em um espaço de uma praça pública, a conduta das pessoas envolvidas e dos passantes seria semelhante à que teriam se estivessem dentro de um templo religioso, guardando silêncio e ouvindo com atenção, pois o sagrado inspira respeito e devoção (ROSENDAHL, 2012b). Um espaço consagrado torna-se lugar sagrado, durante o tempo sagrado, ainda que por um curto período, possibilitando a hierofania. Do mesmo modo ocorreria em um espaço privado posto nas mesmas circunstâncias. Em geral, as igrejas Assembleia de Deus agendam um dia da semana para realizar uma reunião religiosa chamada de culto no lar / culto volante / culto de ação de graças, na residência de um dos componentes do grupo em agradecimento a 
Deus pelas bênçãos recebidas. Para essa reunião são convidados, principalmente, parentes e amigos que normalmente não iriam à igreja. É como se praticassem o seguinte lema: “se as pessoas não vão à igreja, então, a igreja vai até elas". Nesse caso, no momento da reunião, Deus não estaria no templo da igreja, ou somente nele, mas estaria naquela casa compartilhando daquele momento de certa intimidade familiar; Ele estaria atento a todos os presentes e acessível às orações, cânticos e pregação da mensagem bíblica. Mello (2001, p. 93) compreende que “o lugar, como um santuário, exige respeito e estima, convertendo-se em lar, consagrado pelo povo. Por conseguinte, o Criador, o templo, o lar e o lugar são sinônimos". O deslocamento desse grupo de membros da $\mathrm{AD}$ até as residências se justifica pela compreensão dada por Durkheim (1989, p. 503): “o homem que tem verdadeira fé sente invencivelmente a necessidade de difundi-la, para isso ele sai do seu isolamento, aproxima-se dos outros, procura convencê-los, e o ardor das convicções por ele suscitadas vem reforçar a sua”.

\section{Espaço e Lugar sagrado na percepção dos membros da ADJ25A - Igreja Assembleia de Deus Jardim 25 de Agosto, em Duque de Caxias - RJ}

A Igreja Assembleia de Deus Jardim 25 de Agosto - ADJ25A se localiza no Município de Duque de Caxias, Região Metropolitana do Estado do Rio de Janeiro, que abriga 855.048 habitantes em uma área de 467.619 km², expressa na Figura 1. 


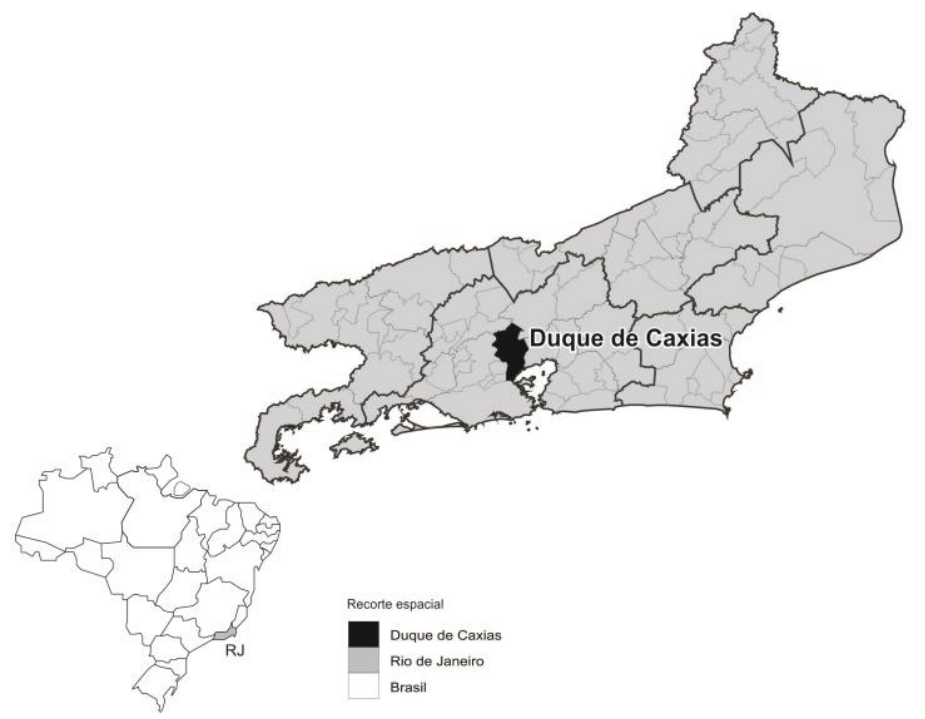

Figura 1 - Localização de Duque de Caxias no Brasil Fonte: A autora, 2013.

Nota: Adaptado de IBGE, 2012.

O Município de Duque de Caxias é habitado por mais de 300.000 evangélicos, correspondendo a 36,8\% da população (IBGE, 2012). Nesse contexto, as Assembleias de Deus totalizam 13,3\% da população caxiense. A igreja matriz objeto deste estudo, a Assembleia de Deus Jardim 25 de Agosto - ADJ25A, responde por 1,23\% dos assembleianos do município. A designação dada a esta Assembleia de Deus refere-se ao seu endereço, o bairro nobre do município de Duque de Caxias - RJ, o Jardim 25 de Agosto.

A ADJ25A é uma das igrejas Assembleias de Deus pioneiras em Duque de Caxias. Tornou-se uma igreja de referência por ter em seu histórico um forte envolvimento com a comunidade na qual está inserida. Nos primeiros anos de seu estabelecimento: (a) os líderes da ADJ25A organizavam regularmente cultos em praças públicas; (b) semanalmente um grupo de membros da igreja utilizava a Kombi da Instituição para distribuir sopa para os moradores de rua da comunidade; (c) nos períodos festivos, a banda e parte dos membros da igreja realizavam passeatas desfilando pelos bairros adjacentes cantando hinos e evangelizando; (d) as vigílias atraiam grande público; e (e) os pontos de pregação eram muito conhecidos nos bairros ao redor - um deles durou cerca de 30 anos. Suas filiais espraiaram-se por dois Estados brasileiros, Rio de Janeiro e São Paulo, somando um total de 1.828 membros. 
A sigla ADJ25A, destacada na Figura 2, foi adotada e usada como um estandarte a fim de dar "ares" mais modernos a uma matriz renovada, mas com um histórico fortemente conservador.

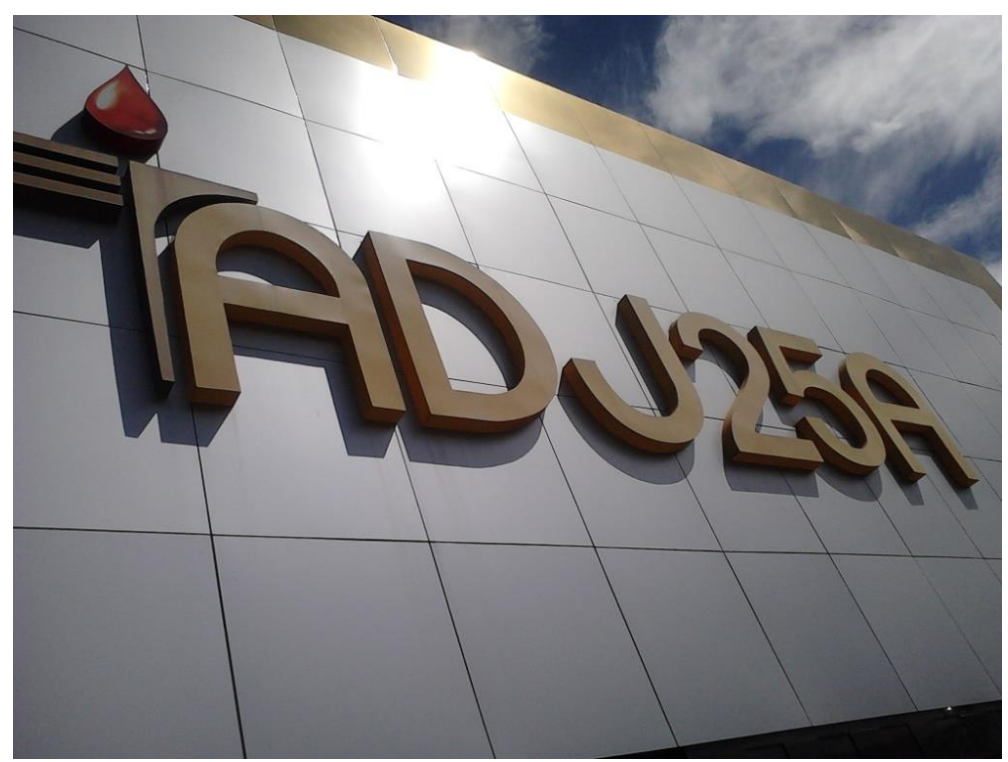

Figura 2 - Fachada do templo da ADJ25A.

Fonte: acervo da autora, 2013.

A ADJ25A foi fundada em 1955 e, durante mais de quatro décadas, a matriz foi pastoreada e as filiais lideradas pelo pastor-presidente Claudionor da Silva Fabricante que, ao se aposentar em 1998, indicou para sua sucessão o teólogo e conferencista pastor Isaías Gomes de Oliveira. O pastor-fundador da ADJ25A, Claudionor da Silva Fabricante, nasceu em agosto de 1924 e faleceu em fevereiro de 2012, aos 88 anos de idade, em consequência de um acidente vascular cerebral. Em sua homenagem, em abril de 2012, a vereadora Juliana Fant Alves, conhecida como Juliana filha do Tião do táxi, propôs à Câmara de Vereadores de Duque de Caxias o Projeto de Lei $\mathrm{n}^{\circ}$ 184/12 no qual requisita que seja denominada Rua Claudionor da Silva Fabricante a atual Rua Evaristo da Veiga, onde está situada a ADJ25A, protagonizando um processo de toponímia no Município.

A percepção dos membros da ADJ25A sobre espaço e lugar sagrado, neste trabalho, é interpretada a partir da observação empírica e da aplicação de um questionário $^{1}$ qualitativo individual aos membros do grupo. As questões estão

\footnotetext{
${ }^{1} \mathrm{O}$ referido questionário se encontra em anexo.
} 
relacionadas à vivência e percepção do/no lugar sagrado. Com o apoio dos líderes religiosos da Instituição, os questionários foram respondidos com muita seriedade.

No início do cabeçalho foi destacada a observação de que o questionário solicitava a opinião individual, não havendo, portanto, respostas corretas ou incorretas, a fim de que o indivíduo se sentisse à vontade e com autonomia para responder. $\mathrm{O}$ mesmo foi elaborado de modo a dispensar a identificação nominal do indivíduo, no entanto, as primeiras perguntas objetivam traçar um perfil dos membros do grupo baseando-se em idade, sexo, escolaridade, envolvimento com a igreja e com a Bíblia Sagrada. Algumas perguntas referiam-se à percepção sobre a existência de espaços mais sagrados do que outros no interior da igreja que freqüentam, a ADJ25A. A respeito do púlpito, local aparentemente tido como mais sagrado, foram elaboradas outras questões mais específicas.

O questionário foi aplicado aos membros da ADJ25A, adolescentes, jovens e adultos, com idade entre 11 e 74 anos de idade, presentes na manhã de 10 de março de 2013, durante a reunião denominada Escola Bíblica Dominical (EBD). Crianças com menos de 11 anos de idade não participaram da pesquisa. Os alunos, professores da EBD, pastores e auxiliares foram orientados pelo co-pastor Lola Ndofusu a responder com autonomia, enfatizando a inexistência de respostas corretas ou incorretas, visto que o objetivo da pesquisa consiste na apreensão subjetiva da percepção individual sobre espaço e lugar sagrado.

As reuniões de EBD ocorrem semanalmente, nas manhãs de domingo, e se caracterizam pela separação dos membros da igreja em diferentes grupos, selecionados de acordo com a faixa etária, o sexo e/ou a atividade ministerial exercida na igreja para estudar o tema bíblico proposto para o dia. Todas as classes da EBD da ADJ25A acompanham a temática da revista Lições Bíblicas, editada pela CPAD.

O grupo participante da pesquisa é composto por 49 homens e 51 mulheres. Dentre eles, 24 adolescentes de 11 a 18 anos, 20 jovens de 19 a 30 anos, 40 adultos de 31 a 50 anos e 16 acima de 50 anos de idade, totalizando 100 pessoas. Em relação à formação intelectual, $22 \%$ dos presentes completaram somente o ensino fundamental, $39 \%$ completaram o ensino médio, $20 \%$ estão cursando a faculdade e $19 \%$ têm nível superior completo. É importante frisar que dentre as 22 pessoas que completaram 
apenas o ensino fundamental, 13 têm entre 11 e 16 anos, estando, portanto, em idade escolar.

Acerca da participação nos departamentos da igreja através do trabalho voluntário, $10 \%$ do grupo não têm compromisso com nenhuma das atividades da Instituição, comportando-se apenas como membro da ADJ25A. Por outro lado, 30\% participam de, no mínimo, dois departamentos simultaneamente e $60 \%$ participam de apenas um. Alguns dos Departamentos, ou ministérios, da ADJ25A são: música, englobando orquestra e ensino musical, dança coreográfica, coral de jovens, de crianças, de adolescentes e de mulheres, artes teatrais, interseção familiar, interseção durante os cultos, evangelismo, diaconato, pastorado, consolidação dos neófitos, recepção, professores da EBD e ação social.

Em relação ao perfil religioso do grupo, apenas $11 \%$ dos participantes apontaram a presença de representantes de outras religiões em sua família, demonstrando uma homogeneidade religiosa em $89 \%$ das famílias representadas. Sobre a leitura bíblica, $37 \%$ responderam que realizam a prática diariamente em sua casa, e $53 \%$ vão à igreja, no mínimo, três vezes por semana.

Quanto à hierarquia de sacralidade dos espaços, 79\% negam a existência de lugares mais sagrados do que outros no interior da igreja. No entanto, 18 participantes que negam essa hierarquia, afirmam ser o púlpito o lugar mais sagrado em questão posterior. Ainda, $70 \%$ reconhecem haver diante do púlpito um comportamento diferente dos demais espaços do templo. Finalmente, $61 \%$ apontam como justificativa para a elevação do púlpito/altar em alguns degraus acima do restante da igreja o fato de otimizar a visibilidade do pregador em referência à platéia. Entre os $21 \%$ que identificaram uma hierarquia de sacralidade nos espaços do templo, o argumento que mais se repetiu defendia que o púlpito é o lugar mais sagrado

"porque ali é o lugar que se transmite a Palavra de Deus".

A Figura 3 mostra os pastores diante do púlpito da ADJ25A durante uma reunião de Santa Ceia. A imagem permite observar os degraus que proporcionam um maior destaque ao lugar em questão. A mesa adornada com trigo e uvas refere-se aos elementos constituintes do ritual de Santa Ceia, o pão e o vinho, e está presente apenas 
nas reuniões destinadas a este ritual. Nas demais reuniões, a organização espacial destaca apenas o púlpito.

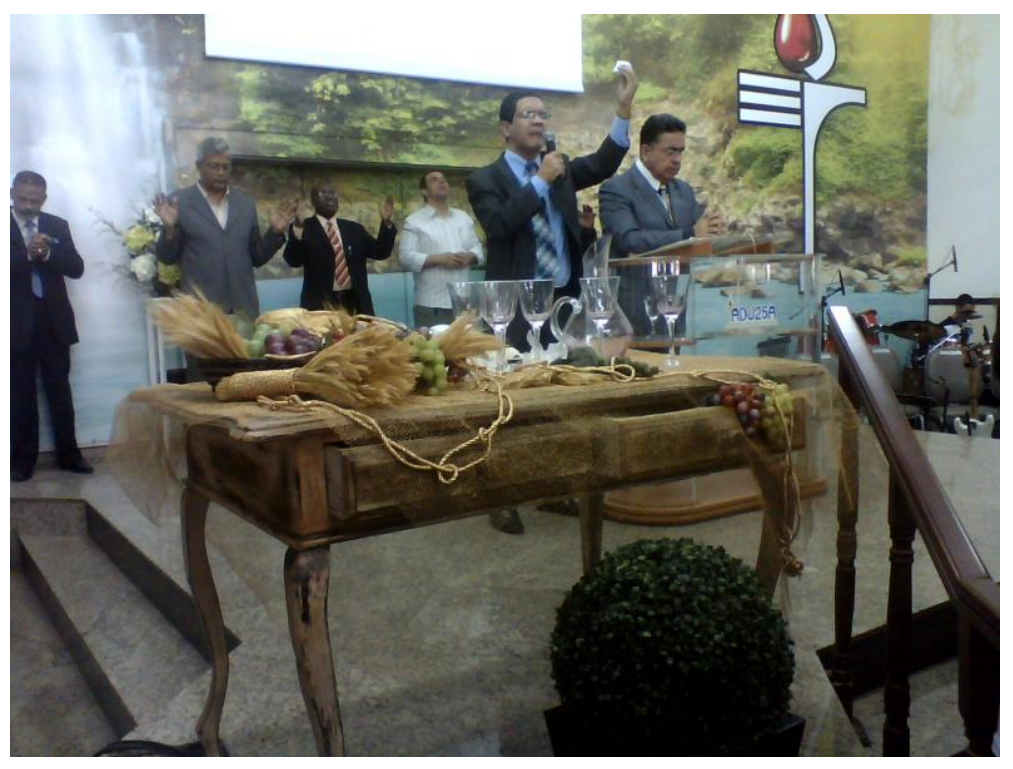

Figura 3 - Púlpito da ADJ25A

Fonte: acervo da autora, 2013.

Os membros da ADJ25A que alegaram a inexistência de hierarquia entre os espaços justificaram sua resposta com frases semelhantes a estas:

"Toda a casa do Senhor é sagrada".

"Todo lugar é sagrado na casa de Deus".

"Pra mim todo lugar é sagrado no templo".

"O lugar onde a gente escolhe para orar é o mais sagrado".

"Do portão da igreja pra dentro, todos os espaços são sagrados".

Sobre a questão "na sua opinião, como um lugar torna-se sagrado?", a maioria das respostas apontavam a necessidade de "consagração ao Senhor e verdadeira presença de Deus" para que um lugar se torne sagrado. Além disso, foram obtidas as seguintes afirmações:

“Através da presença de Deus”.

"Quando reverenciamos a Deus".

"Quando preparamos para cultuá-Lo". 


\author{
"Quando nos relacionamos com Deus". \\ "Quando existe a presença do Espírito Santo". \\ "Quando nesse lugar nós vemos milagres acontecerem”.
}

As respostas obtidas confirmam a afirmação feita ao longo deste trabalho de que, na concepção assembleiana, um lugar torna-se sagrado através da consagração a Deus, feita pelos crentes. Para eles, a sacralidade do lugar pode ser percebida por meio do sentir a presença de Deus e do Espírito Santo, o que possibilitaria a manifestação do poder do sagrado através da realização de milagres. Portanto, o grupo de crentes ora consagrando o lugar, espaço-tempo, a Deus e, através do sentir a presença de Deus, a consagração é ratificada. Na interação desses elementos - grupo de crentes concentrado em oração a Deus, lugar sagrado, presença de Deus - para o grupo estudado a manifestação do sagrado torna-se possível. Rosendahl (2012) enfatiza que podem ser distinguidos e delimitados vários tipos de espaços sagrados, mas dificilmente se podem fazer generalizações sobre os princípios de lugar sagrado, pois sua percepção varia de grupo para grupo.

Nesse contexto, uma jovem senhora de 45 anos de idade, com nível superior completo, se expressou nas seguintes palavras:

\footnotetext{
"Porque se a minha [casa] não for sagrada em primeiro lugar a minha vida não o será. [minha casa e minha vida se tornam sagradas] Tendo Deus, o Senhor como o centro e tendo uma vida de comunhão".
}

$\mathrm{O}$ argumento exposto defende que o lugar sagrado se estende do templo para os espaços cotidianos como a casa e a própria vida. Neste sentido, uma jovem de 29 anos, com nível superior completo, revelou o seguinte pensamento:

"Qualquer lugar onde eu possa falar com Deus [é sagrado]. Porque Deus está em toda parte. [um lugar torna-se sagrado] Quando você o separa para Deus. Na verdade, todos nós somos 
morada do Espírito Santo, portanto, nosso corpo e nossa mente são ‘locais’ sagrados”.

A jovem qualifica como lugar sagrado o próprio corpo, justificando ser a morada do Espírito Santo. Ponderando sobre esse enfoque, o geógrafo Tuan $(1983,154)$ defende a possibilidade de considerar um indivíduo como lugar, exemplificando que "para a criança pequena, os pais são seu 'lugar' primeiro. No entanto, o pesquisador adverte que "a idéia de uma pessoa como 'lugar' ou 'lar' não é aceita de imediato" (ibidem, p.154).

Dentre os que responderam a questão "qual o item (alguma pessoa, algum espaço ou algum objeto) que você considera mais sagrado?", 38 pessoas julgaram ser a Bíblia Sagrada, 13 defenderam ser o púlpito/altar, 7 escolheram a igreja, 5 optaram por Deus, 2 pelo Espírito Santo e 2 apontaram a Santa Ceia. Cada um dos seguintes itens foi indicado por apenas uma pessoa como o mais sagrado: Jesus Cristo, a EBD, o próprio lar, o próprio quarto, o próprio corpo, a comunhão com Deus, a presença de Deus, o óleo da unção, a revista da EBD e os pastores, presbíteros e irmãs de oração. No entanto, um dos participantes foi enfático ao expressar seu pensamento na seguinte assertiva:

"[o item mais sagrado é] A Palavra do Senhor, não a Bíblia ‘livro' sim o que ela contém”.

Esta colocação expressa a teoria defendida por estudiosos e pelas lideranças evangélicas de que é o conteúdo dos textos bíblicos que tem o caráter sagrado, delegando ao livro apenas a tarefa de ser o portador da mensagem divina. Tal afirmação confirma, em alguma medida, as reflexões de Mircea Eliade sobre a manifestação do sagrado em objetos - púlpito/altar e livro/a Bíblia.

\section{CONSIDERAÇÕES FINAIS}


Guiados pela questão inicial deste estudo, Como o grupo constrói, percebe e vivencia o lugar sagrado?, foi possível interpretar os resultados obtidos por meio da análise dos questionários e da observação empírica. Através do exame das respostas dadas às questões propostas, pode-se concluir que, na percepção dos membros da ADJ25A participantes desta pesquisa, o espaço sagrado é separado e consagrado, seja ele um templo, a própria casa ou um espaço público.

Em relação à construção do lugar sagrado, os membros do grupo o fazem através da consagração a Deus, com orações e invocações. Ao refletir sobre suas próprias crenças, grande parte dos indivíduos consultados percebe o espaço do templo como sendo homogeneamente sagrado, por ser todo ele igualmente consagrado a Deus. No entanto, o espaço é vivenciado de modo heterogêneo. Suas práticas e ritos no tempo sagrado, como o comportamento mais reverente diante do púlpito, o diferencia dos demais espaços do templo, demonstrando uma valoração superior deste lugar, ainda que inconscientemente, pois o comportamento subjetivo do devoto é que se torna primordial na manifestação do sagrado. O espaço e o tempo da vivência favorecem a identidade do religioso no grupo sócio-religioso que ele atua.

Os participantes desta pesquisa demonstraram o envolvimento e a percepção do lugar. As respostas obtidas reafirmaram os pensamentos comungados por inúmeros religiosos, além de impor uma futura reflexão sobre o corpo humano como um lugar sagrado. A observação empírica possibilitou interpretação das práticas religiosas do homem religioso assembleiano no seu construir, no seu perceber e na sua vivência no lugar sagrado. Desse modo, este estudo cumpriu o seu propósito de proporcionar uma análise reflexiva sobre espaço e lugar sagrado por meio da interpretação da percepção dos membros da ADJ25A, além de configurar-se como uma introdução a uma agenda de pesquisa sobre o pentecostalismo clássico brasileiro.

\section{REFERÊNCIAS}

ARQUIVO DA ASSEMBLEIA DE DEUS JARDIM 25 DE AGOSTO. [Dados da Igreja Assembleia de Deus Jardim 25 de Agosto]. Duque de Caxias, 2007.

CORRÊA, R. L. Espaço: Um Conceito - Chave. In: CASTRO, I. E.; GOMES, P. C. C. (Org.). Geografia: Conceitos e Temas. Rio de Janeiro: Bertrand Brasil, 1995. 
DURKHEIM, E. As Formas Elementares da Vida Religiosa: o sistema totêmico na Austrália. São Paulo: Paulinas, 1989.

ELIADE, M. O Sagrado e o Profano: a essência das religiões. São Paulo: Martins Fontes, 2010.

FRESTON, P. Breve história do pentecostalismo brasileiro. In: ANTONIAZZI, A. et al (Org.). Nem anjos nem demônios: interpretações sociológicas do pentecostalismo. Petrópolis: Vozes, 1994.

GIL FILHO, F. S. O espaço sagrado: estudos em geografia da religião. 2. ed. Curitiba: Ibpex, 2012.

. Por uma Geografia do Sagrado. In: MENDONÇA, F.;KOEZEL, S. (Org.) Elementos de Epistemologia da Geografia Contemporânea, Curitiba: Editora UFPR, 2002.

GIL FILHO, F. S.; GIL, A. H. C. Identidade religiosa e territorialidade do sagrado: notas para uma teoria do fato religioso. In: ROSENDAHL, Z; CORRÊA, R. L. (Org.) Religião, identidade e território. Rio de Janeiro: EdUERJ, 2001.

HOLZER, W. O conceito de lugar na geografia cultural-humanista: uma contribuição para a geografia contemporânea. GEOgraphia, Niterói, v. 5, n.10, 2003.

IBGE. Base de Dados do IBGE. Disponível em $<$ http://mapas.ibge.gov.br/website/divisao/viewer.htm>, <http://www.ibge.gov.br/cidadesat/> e <http://www.sidra.ibge.gov.br/> Acesso em setembro de 2012.

MARIANO, R. Neopentecostais: Sociologia do novo pentecostalismo no Brasil. 2. ed. São Paulo: Edições Loyola, 2005.

MELLO, J. B. F. Descortinando e (Re)pensando categorias espaciais com base na obra Yi-Fu Tuan. In: CORRÊA, R. L.; ROSENDAHL, Z. (Org.). Matrizes da Geografia Cultural. 1ed. Rio de Janeiro: EdUERJ, 2001.

A humanização da natureza - uma odisséia para a (re)conquista da natureza. In: SILVA, S. T.; MESQUITA, O. V.(Org.) Geografia e questão ambiental. Rio de Janeiro: IBGE, 1993

Geografia humanística: a perspectiva da experiência vivida e uma crítica radical ao positivismo. In: Revista Brasileira de Geografia. Rio de Janeiro: IBGE, 52, n. 4, 1990.

NORTON, W. Cultural Geography: themes, concepts, analyses. Oxford: Oxford University Press, 2000.

PEREIRA, C. J. Do Sagrado Ontológico à Forma Simbólica: o Espaço Sagrado como categoria de análise na Geografia da Religião. In: V Simpósio Paranaense de Pós- 
Graduação e Pesquisa em Geografia, 2010, Curitiba. Anais do V Simpósio Paranaense de Pós-Graduação e Pesquisa em Geografia, 2010.

PEREIRA, C. J. ; GIL FILHO, S. F. Geografia da Religião e Espaço Sagrado: diferenças entre as noções de lócus material e conformação simbólica. Ateliê geográfico (UFG), v. 6, 2012.

Geografia da Religião, Espaço Sagrado e Pentecostalismo: Análise de uma Espacialidade Pentecostal. In: Religião e Sociedade: o espaço do sagrado no século XXI, 2009, Curitiba. V Seminário Nacional Religião e Sociedade: O Espaço do Sagrado no Século XXI. Caderno de Resumos, 2009.

ROSENDAHL, Z. Primeiro a obrigação, depois a devoção: estratégias espaciais da Igreja Católica no Brasil de 1500 a 2005. Rio de Janeiro: EdUERJ, 2012a.

O sagrado e sua dimensão espacial. In: CASTRO, I. E.; GOMES, P. C. C.; CORRÊA, R. L. (Org.) Olhares geográficos: modos de ver e viver o espaço. Rio de Janeiro: Bertrand Brasil, 2012b.

A Dimensão do Lugar Sagrado: ratificando o domínio da emoção e do sentimento do ser-no-mundo. In: CARNEIRO, S. S.; SANT'ANNA, M. J. G. (Org.). Cidades: olhares e trajetórias. Rio de Janeiro: Garamond, 2009.

Apresentação. In: ROSENDAHL, Z.; CORREA, R.L. (Org.) Introdução à Geografia Cultural. Rio de Janeiro: EdUERJ, 2003a.

Espaço e Religião: uma abordagem geográfica. 2a Edição. Rio de Janeiro: EdUERJ, 2002.

Lugares sagrados e sacralizados: as múltiplas faces do simbolismo. In: VI Encontro Nacional da ANPEGE. Ceará, 2005.

Os caminhos da construção teórica: ratificando e exemplificando as relações entre espaço e religião In: ROSENDAHL, Z.; CORREA, R.L. (Org.) Espaço e cultura: pluralidade temática. Rio de Janeiro: EdUERJ, 2008.

O sagrado e o espaço. In: CASTRO, I. E.; GOMES, P. C. C.; CORRÊA, R. L. (Org.) Explorações geográficas: percursos no fim do século. Rio de Janeiro: Bertrand Brasil, 1997.

O espaço, o sagrado e o profano. In: ROSENDAHL, Z.; CORREA, R.L. (Org.) Manifestações da Cultura no Espaço. Rio de Janeiro: EdUERJ, 1999.

Espaço, Religião e Cultura: Dimensões de Análise. In: ROSENDAHL, Z.; CORRÊA, R. L. (Org.) Introdução à Geografia Cultural. Rio de Janeiro: Bertrand Brasil, 2003b.

SANTOS, A. P. O papel do geógrafo no mundo. Portal eletrônico Diário de Cuiabá, Cuiabá - MT - Brasil, 29 maio 2007. Disponível em 
$<$ http://www.diariodecuiaba.com.br/detalhe.php?cod=287055> Acesso em janeiro de 2013.

TUAN, Y. F. Topofilia. São Paulo, DIFEL, 1980.

Espaço e lugar. São Paulo, DIFEL, 1983. 


\section{QUESTIONÁRIO SOBRE PERCEPÇÃO DE ESPAÇO E LUGAR SAGRADO}

Este questionário é sobre opinião individual, portanto, não há respostas corretas ou incorretas.

Data:

Idade:

Sexo:

Grau de escolaridade: ( ) Ensino Fundamental ( ) Ensino Médio

( ) Ensino Superior incompleto ( ) Ensino Superior completo

1. Você faz parte de algum ministério (grupo específico) na sua igreja? Se sim, qual (is)?
( ) $\operatorname{sim}$
( ) não

2. Quantas vezes por semana você vai à igreja?

3. Você costuma ler a Bíblia Sagrada em casa? Se sim, quantas vezes por semana? ( ) $\operatorname{sim}$ ( ) não

4. Em sua família (moram na mesma casa) há representantes de outras religiões? ( ) $\operatorname{sim}$ ( ) não

5. Na sua opinião, há espaços mais sagrados do que outros no interior da sua igreja? Se sim, quais? ( ) $\operatorname{sim}$ ( ) não

6. Por que você considera esse lugar como o mais sagrado?

7. Na sua opinião, como um lugar se torna sagrado?

8. Qual o item (alguma pessoa, algum espaço ou algum objeto) que você considera mais sagrado?

9. Na sua opinião, no púlpito há um comportamento diferenciado dos demais espaços da igreja?

$$
\text { ( ) } \operatorname{sim}
$$

( ) não

10. O púlpito da igreja se destaca por se localizar alguns degraus acima do nível restante da igreja. Na sua opinião, qual é a justificativa para esse desnível?

( ) melhora a visibilidade do pregador

( ) o púlpito é o lugar mais sagrado

( ) outro. Qual?

Obrigada pela colaboração!!! 
Recebido: 15/08/2014

Received: 08/15/2014

Aprovado: 19/112014

Approved: 11/19/2014 